\title{
Thinking on Morality and Happiness
}

\author{
Ping Yao \\ Ideological \& Political Department of Jiujiang Univsersity, Jiujiang, Jiangxi, 332005
}

\begin{abstract}
Everyone lives in certain social environment. As one special social value form, morality is one criterion approach to carry out social conditioning by people through good \& evil assessment, and one practical spirit of human self-improvement. Morality aims at making people happy. Happiness is not only the life aim pursued by an individual, but also the final goal pursued by human society.
\end{abstract}

KEYWORD: Morality; Happiness; Scale of Happiness; Significance of Morality

Each of us can find that we are living in a society full of criterion and morality dogma once we are born. We can confirm that morality is useful social system; however, why should we comply with morality? Whether the compliance with moral principles can enhance our life happiness or not? These questions often reappear in our life. The issue of morality and happiness has been the concern of human as well as one issue of different opinions and no consensus since ancient times. We will discuss it here in below.

\section{MORALITY AND ROLE OF MORALITY}

In our daily life, we say someone is moral, namely, he/she is a good man/woman generally; we say some is immoral, namely, he/she is a bad man/woman. "Moral" and "immoral" here refer to "good (kind) and bad (evil)" or "right (proper) and wrong (improper)" substantively; furthermore, they are used to assess human and behavior of human. Then, what is morality? The word "morality" is one compound word of "doctrine" and "virtue". In ancient Chinese, "doctrine" refers to laws and rules of things movement \& change; in the combination use of "doctrine" and "virtue", "doctrine" refers to laws, rules and criterions of interpersonal relationship instead of general laws and rules. "Virtue" refers to the gain after cognition and implementation of "doctrine". Liu Xi of the Eastern Han Dynasty explained "virtue" as gain. Namely, "virtue" refers to the ability that enables oneself and others to achieve gains after properly dealing with things between people. Therefore, "doctrine" and "virtue" were separated initially; "doctrine" is the basis and fundament of "virtue", while "virtue" is the realization of "doctrine". However, "doctrine" and "virtue" become one word with wider definitions in later historical development; it does not only refer to some qualities and virtues specially possessed by human, but also some laws, rules and requirements specially possessed by human society. Morality is the unity of external moral standard and internal virtues. The outward manifestation of moral standard is custom as well as rules and regulations, etc; its strength is moral evaluation. The outward manifestation of virtue is moral behavior; its mechanism of action is innermost belief.

In real life, two aspects constituting moral system (moral rule and virtue) are interactional and mutually beneficial. The moral rules and rules of society develop qualities and virtues of individual, while the qualities and virtues of individual can become guarantee for morals and rules to play a role conversely; one aspect shall be damaged and cannot exist truly for the absence of the other aspect. Two aspects of morality correspond to two important functions of morality: first, the coordination function of morality to adjust relationship between humans and maintain social order and stability; second, the incentive function to encourage human to transform their subjective world and objective world to perfect themselves and society and achieve the ideal state gradually.

Morality is the behavior out of principles. Then, why human should be moral? Or rather, what is the basis for establishment of moral principle? The basis of morality comes from sensibility desire of humanity empirically. If we study humanity in accordance with experience and rationality, we will find that all humans have many common needs, 
desires and aims; for example, it seems that we all need friendship, love, happiness, freedom, creativity and stability in our own life, which does not meet needs of ourselves, but also needs of others. In order to meet there needs, the moral principles established and observed by humans should encourage humans to be pleased to cooperate mutually to avoid fear without worrying about being killed, damaged or cheated. Therefore, morality is established for needs of humans as it is recognized that it is of significance to live by cooperating. Humans can live peacefully and happily with full creativity and rich meaningfulness as far as possible by observing moral principles.[1] Morality is the indispensable living style of humans. It brings us rules to live together with others and sets limits for our desires and behavior. It tells us what is allowed and unallowed.

\section{HAPPINESS AND SCALE OF HAPPINESS}

The pursuit of happiness is the life power of each person. Happiness is the life state achieved after realizing human's value partially, meeting needs of human rationally and obtaining success of life development, the active and positive mental experience generated, and the organic unity of objective life state and subjective mental experience. Then, how to judge whether we are happy or not? When will we become happy? Whether there is unified standard for "happiness"? If any, what is the standard for "happiness"? If our happiness depends on comparison with others, how happy are the people around us? In fact, it is difficult to have definite answers for these questions. Although there are definite answers for them, these answers are of no use for improvement of our happiness.

"Am I happy?" This question implies two different opinions of happiness in question itself: we are happy or unhappy. Happiness becomes one end point in this understanding; once we arrive at it, the pursuit of happiness ends as well. However, this end point does not exist and the persistence of this misunderstanding only can result in dissatisfaction and failure mentality. [2] In our life, the composition of happiness is extended continuously; its extending rules are similar to the need pyramid theory of Maslow, a psychologist of USA. Maslow divides needs of human into five levels, namely, the physiological needs, safety needs, affiliation and love needs, esteem needs and needs for selfactualization. The lowest level is physiological needs; the highest level is the needs for selfactualization. The higher level can be shown only after meeting the lower level; for example, if your physiological needs cannot be met, have little food to eat and try to live, your higher needs shall not be shown at that time. However, your needs of relatively higher level can be shown after meeting needs of lower level. The maximum and long-lasting happiness is self-actualization. The self-actualization refers to persistent, continuous and complete pursuit of own intrinsic value by human in a certain sense. Therefore, we can be happier forever, and no one lives at perfect life status all the while without any desire or need.

When people's primary material demands are not satisfied, it is rather easy to explain why they don't feel happy. However, the reason for unhappiness for the majority of people can't be explained in the way that they are not satisfied with primary material demands in our current society. More and more people intend to solve a paradox--"what the wealth brings to us seems not to be happiness." Aristotle told us in his Ethika Nikomachea: Happiness is the achievement of morality. Human's virtue is the quality and capacity that can make an individual a philanthropist and assist him to successfully fulfill his activities. Happiness is the activities to apply this capacity.

As the material wealth increases, the social development creates necessary conditions for people to pursue happiness at most, but it will not bring people greater and durable happiness necessarily. However, people in current society are always fond of taking current sensual pleasures and satisfaction resulting from material life as happiness. It can't be denied that the increase of material wealth and improvement of living conditions are happiness. However, they are merely part of happiness, but not the entire contents of happiness, which can only induce the superficial layer sense of feeling, but can't bring the essence of deep sense of happiness, since wealth and interest are only the implorations floating on the surface. For instance, it is limited to increase the life quality of an individual with money. Money is useful in some instances, while useless in some other conditions. All the benefits are conditional, occasional and uncertain, and can't be sufficient to make life meaningful or bring people happiness. The mode of life for obtaining happiness is to attain morality rather than pursue benefits. Or rather, happiness doesn't result from benefit, but from doctrine and morality (gain).[3] Therefore, the happiness in the true sense must be related to the perfection of internal value, virtue and human nature of human, and go deep into people's spiritual level. The most durable happiness lies in people's creative activities by all means and in the process of constantly pursue of the fundamental object of life.

\section{SIGNIFICANCE OF MORALITY}

Pursuit of happiness is the issue of individuals. However, people always live in groups. Existence of human is dependent on each other, who share the 
coexistence state with other people. The significant mission of morality is to determine value orientation in aspects of relationship among individuals and whole as well as among individuals. Seen from human history and reality, there are significant differences among the value orientation established for different social moralities, among which, taking the whole and individual as orientations are two basic value orientations throughout history of man. In today's world, both orientations have their own comparative advantages, and it's hard to tell the good from bad by comparison. However, this type of social orientation, also the social guiding, exerts a tremendous influence on pursue of the individual for happiness.

As the general value orientation of the society, morality will under no circumstances guide the value pursue of social members only through publicity. In even more circumstances, the state will resort to numerous measures (measures of economic, politics, law, public opinion, etc) and utilize multiple strengths (legal, political, moral, cultural strengths) to carry out the value orientation determined. Just for this reason, whether individual value is in line with that of the society is related to the happiness of an individual. Generally speaking, the consistency with social orientation does not necessarily mean that an individual will obtain happiness. However, the inconformity with social orientation is certainly difficult for an individual to acquire happiness.

As the social value orientation, morality is always embedded in certain general value standard and principal. When social orientation gives expression to value standard, it will become the fundamental scale for the society to measure right and wrong, good and evil, and beauty and ugliness of people. When social orientation is reflected in value principle, it will become the fundamental principle for the society to regulate the behavior activities and even ideology of people. If we say that the influence of social value orientation on people's pursuit is not so direct in that way, the social value standard and behavior rule will have direct guiding, regulating and restricting function on people's pursuit. This type of function shall be realized through a determined restriction mechanism. Restriction mechanism of society in the contemporary age includes soft constraint (such as morality, public opinion) and rigid restrictions (such as law, policy). Any type of restriction will exert an influence on pursue of people. As a general rule, pursuit that conforms to social value standard and behavior rule will be recognized, admired, and even supported and fostered by the society, and thus it is easier to succeed.

Whether as social value orientation or as social value standard and behavior rule, morality is the social condition for people to pursue happiness, but it doesn't constitute content of happiness in itself. As for happiness, morality only has the significance of instrument. However, when morality is served as the internal quality and virtue of an individual, it has both significance of condition and instrument as well as that of elements and objective [4]. We have learnt from experience that, favorable moral character is the essential psychological quality for an individual to realize his happiness, which can be served as the fine atmosphere built for an individual to pursue his happiness. Moreover, an individual with favorable moral quality can earn respect from other people and the society, and an individual can obtain selfsatisfaction. All these are the significant contents for an individual to obtain happiness.

\section{REFERENCES}

[1] Written by (America) Jacques-Tillo et al. and translated by Cheng Lixian, Ethnic and Life, Beijing World Publishing Corporation, 2008:27.

[2] Written by Shachar and translated by Wang Bing and Liu Junjie, Approach to Happiness, Contemporary China Publishing House, 2009:7.

[3] Written by Zhao Tingyang: Discussion on Possible Life: A theory on Happiness and Justice, China Renmin University Press, 2004:17.

[4] Jiang Chang: Reflection on Issues of Morality and Happiness, Academic Journal of Hubei University, 1999 (3): 109 